\title{
MULHERES FRENTE À RECESSÃO ECONÔMICA E A AUSTERIDADE: UMA INTERPRETAÇÃO DA ECONOMIA
} FEMINISTA

\author{
Women facing economic recession and austery: an interpretation of the \\ feminist economy
}

\author{
Iriana Lima CADÓ \\ Instituto de Economia da Unicamp, Campinas, Brasil \\ iriana.cado@gmail.com \\ Juliane da costa FURNO \\ Instituto de Economia da Unicamp, Campinas, Brasil \\ jujufurno@gmail.com
}

\begin{abstract}
RESUMO
Objetivo: O presente artigo tem por objetivo lançar um olhar, sob o viés da economia feminista, para trajetória das mulheres no mercado de trabalho diante da recessão econômica (2014-2015) e posteriormente diante da aplicação de um conjunto de políticas de austeridade. A hipótese que circunda este estudo é que homens e mulheres por assumirem papéis sociais distintos, consequências da consolidação de um imaginário social sobre o que é ser homem e ser mulher, são impactados diferentemente. A economia feminista vem se debruçando na tentativa de interpretar as diferentes trajetórias destes sujeitos na esfera produtiva, questionando a universalidade e neutralidade das categorias convencionais, apontando para a ideia de que decisões econômicas se colocam de forma distinta para os atores sociais. Para isso lançaremos mão da discussão teórica da crítica da economia feminista ao pensamento econômico clássico, e olharemos para os indicadores oficiais do IBGE para correlacionar com o processo vivenciado no Brasil no período citado. PALAVRAS-CHAVE: Economia feminista. Mercado de trabalho. Austeridade. Recessão econômica. Gênero.
\end{abstract}

\begin{abstract}
Objetive: Under the bias of the feminist economy, this study cast a look at the trajectory of women in the labor market in the face of the economic recession (2014-2015) and the ensuing set of austerity policies. The hypothesis surrounding this research is that men and women, for assuming different social roles, consequences of the consolidation of a social imaginary about what it is to be a man and a woman, are impacted differently.

The feminist economy has been focusing on the attempt to interpret the different trajectories of these subjects in the productive sphere, questioning the universality and neutrality of conventional categories, and pointing to the idea that economic decisions are placed differently for social actors. For this, we will make use of the theoretical discussion of the critique of feminist economics to classical economic thought, and we will look at the official indicators of the IBGE to correlate with the process experienced in Brazil in the mentioned period.

KEYWORDS: Feminist economy. Labour Market. Austerity. Economic recession. Gender.
\end{abstract}

\section{Classificação JEL:}

Recebido em: 06-03-2020. Aceito em: 06-07-2020. 


\section{INTRODUÇÃO}

A economia brasileira passou por um profundo período de crise econômica recente, com queda de aproximadamente 7\% do seu PIB entre os anos de 2015 e 2016 . A queda na atividade econômica precedida de um ano de déficit fiscal - 2014 - reascendeu o debate sobre as alternativas de política econômica para a retomada do crescimento e o equilíbrio fiscal. Nesse ínterim, a crise econômica foi sobreposta a uma crise política que levou ao afastamento da Presidenta Dilma Rousseff e a assunção do seu vice Michel Temer, que foi conduzido ao cargo embasado em um programa de austeridade fiscal e reversão das principais ações de política social da era petista, embalado na insígnia de "Uma Ponte para o Futuro".

Embora desde o ano de 2015 a opção pela austeridade fiscal já vinha sendo a tônica do governo Dilma, era é radicalizada com a ascensão do pemedebista, concebida sob um projeto não apenas de contração fiscal quanto, também, de reformas estruturais, dentre as quais a nova regra fiscal referendada na EC 95 e a Reforma Trabalhista.

O presente artigo parte da premissa de que momentos de crise econômica e de opções de política centrada no corte de gastos, não apenas são incólumes no que tange as possibilidades de retomado do crescimento econômico, quanto tem resultados distintos - e desiguais - no que tange aos impactos sobre homens e mulheres.

Nosso objetivo, portanto - nesse artigo - é apresentar as transformações no mercado de trabalho para homens e mulheres em duas situações correlatas, porém, com características próprias. A primeira delas é referente aos primeiros impactos da crise econômica sob a situação laboral de homens e mulheres (2015-2016) e a segunda é demonstrar as características da dinâmica do mercado de trabalho a partir da opção mais clara pela política de austeridade fiscal (2016-2018).

Partimos da hipótese de que as formas distintas de impacto para homens e mulheres na crise e na austeridade não podem ser, simplesmente, diagnosticadas. É preciso instrumentos que desvendem a natureza própria da desigualdade de gênero. A ciência econômica, principalmente na sua acepção tradicional ortodoxa, tem sido - historicamente - negligente na compreensão as diferenças de gênero. Mesmo quando essa variável está presente, como em Becker (1965), a superficialidade da análise com ausência de elementos históricos e políticos, os levam a naturalizar as desigualdades de gênero, 
concebendo que a divisão sexual do trabalho é parte da lógica do homus economicus na busca de maximização da utilidade marginal.

Visando ofertar uma explicação mais complexa e que vá além da superficial constatação das diferenças de gênero no mercado de trabalho, nosso trabalho repousa sob a perspectiva da "Economia Feminista", uma corrente de análise econômica que busca suprir essa lacuna ao historicizar as relações sociais de gênero e desconstruir os mitos da suposta neutralidade das categorias econômicas tradicionais.

Assim, o presente artigo está dividido em 4 partes, contando com essa breve introdução. Na segunda parte recorremos a uma revisão bibliográfica acerca da Divisão Sexual do Trabalho e dos pressupostos de crítica política e epistemológica da Economia Feminista, visando fornecer o sólo teórico no qual repousa a análise dos indicadores selecionados. Na segunda parte apresentamos uma caracterização política e econômica dos governos petistas e nossa leitura dos fatores que precederam a desaceleração e a posterior crise econômica deflagrada em 2015. Além disso, traçamos uma análise breve desse período e do debate em torna das opções contracionistas para, posteriormente, passar à análise dos dados das especificidades da trajetória no mercado de trabalho de homens e mulheres frente à crise e a austeridade fiscal. Por fim passamos as considerações finais.

\section{UM OLHAR DA ECONOMIA FEMINISTA PARA AS MULHERES NO MERCADO DE TRABALHO: UMA CRÍTICA À ECONOMIA CLÁSSICA}

Questionar a neutralidade e a objetividade das análises econômicas têm sido a preocupação do que veio a se constituir como "economia feminista". Dessa forma, o pressuposto norteador é de que conhecimento é algo socialmente situado, e, portanto, um campo de disputas. Nesse sentido, o avanço do movimento de mulheres jogou luz às epistemologias dominantes, apontando que não há debate nas ciências que seja neutro e nem absolutamente objetivo. Assim, a crítica da economia feminista passa necessariamente pela construção de uma epistemologia, ou seja, a construção de um campo o qual passa a considerar o lugar e as especificidade da realidade das mulheres. 


\title{
2.1 A ampliação do conceito de trabalho: esfera produtiva, reprodutiva e
}

\section{a divisão sexual}

O aumento da participação feminina no mercado de trabalho em praticamente todas as atividades econômicas é uma conquista do século XX. Contudo, a realidade das mulheres no mercado de trabalho é fortemente marcada por relações sociais complexas e contraditórias, nos quais é possível observar avanços e recuos.

Para compreender a especificidades da trajetória das mulheres no mercado de trabalho, torna-se indispensável o entendimento do conceito de "divisão sexual do trabalho". O conceito de "Divisão Sexual do Trabalho" surge no arcabouço da tradição de pensamento da Sociologia Francesa, que buscou romper com os paradigmas dominantes de análise das relações sociais, ampliando o conceito de trabalho e incorporando a dimensão gênero à interpretação desta esfera. Segundo Hirata e Kergoat (2007), o sentido deste conceito tem por objetivo procurar as nascentes das desigualdades de gênero e, portanto, compreender a natureza do sistema, isto porque - para elas - falar de divisão sexual do trabalho "desprovido de qualquer conotação conceitual, remete apenas a uma abordagem que descreve os fatos, constata as desigualdades, mas não organiza esses dados de forma coerente (HIRATA \& KERGOAT, 2007, p. 599). Sendo assim para as autoras outrora mencionadas, a divisão sexual do trabalho é

\begin{abstract}
A forma de divisão do trabalho social decorrente das relações sociais entre os sexos; mais do que isso, é um fator prioritário para a sobrevivência da relação social entre os sexos. Essa forma é modulada histórica e socialmente. Tem como características a designação prioritária dos homens à esfera produtiva e das mulheres à esfera reprodutiva e, simultaneamente, a apropriação pelos homens das funções com maior valor social adicionado (políticos, religiosos, militares etc.). (...) Essa forma particular da divisão social do trabalho tem dois princípios organizadores: o princípio de separação (existem trabalhos de homens e trabalhos de mulheres) e o princípio hierárquico (um trabalho de homem "vale" mais que um trabalho de mulher) (HIRATA E KERGOAT, 2007, p. 599).
\end{abstract}

Ou seja, a divisão sexual do trabalho tem dois princípios elementares: o da separação e da hierarquização. O da separação consiste no fato de que existe o trabalho de homem e trabalho de mulheres. Isso dá origem a dois tipos distintos de trabalho. $\mathrm{O}$ primeiro deles é denominado de "reprodutivo" e é, prioritariamente, exercido na esfera doméstica e socialmente atribuído às mulheres. O segundo elemento da coexistência é o do trabalho produtivo, que compreende aquele que resulta na produção de bens ou serviços 
com valor econômico e monetário no mercado e que é conferido aos homens. Não somente o trabalho é "divido" levando em consideração o elemento sexual, mas - sobretudo - esses trabalhos são hierarquizados, sendo objeto de valoração distinta e desigual nas sociedades patriarcais. A hierarquização baseia-se na ideia de que os trabalhos produtivos possuem maior valor do que o reprodutivo. É sob este espectro que mulheres e homens são socializados na estrutura familiar e nas outras instituições tais como igreja, escola, entre outros, constituindo o prisma da desigualdade sob o qual as mulheres são inseridas no mercado de trabalho.

Para Hirata (2002) o princípio da "divisão sexual do trabalho", portanto, acaba por materializar a ideia da não admissão de que a esfera produtiva seja um "lugar de pleno direito" das mulheres, ou seja, que a inserção das mulheres na esfera produtiva é consequência de uma demanda conjuntural, como a necessidade de complementação de renda familiar por um certo período de tempo. Sendo essa inserção circunstancial não necessitaria gozar dos mesmos direitos que os homens, justificativa para a precarização nas formas de contratação e nos diferenciais de rendimentos.

Deste modo, as mulheres nunca prescindiram de exercer as tarefas reprodutivas na esfera privada, condicionando sua inserção na esfera produtiva a possibilidade de conciliação da carga de trabalho no âmbito doméstico, conformando historicamente um quadro no qual as mulheres são as maioria entre a população pobre, desempregada, que ocupa postos de trabalho informais e que detém os menores rendimentos. É a partir dessa realidade que percebemos a importância do papel no Estado na efetivação de políticas e programas que deem respostas a esta demanda social, constituindo equipamentos públicos que socialize as tarefas exercidas no âmbito doméstico, como creches e escolas de tempo integral, que favoreçam o aumento do tempo disponível das mulheres e promovam sua autonomia.

A divisão sexual do trabalho, portanto, não é neutra (NOGUEIRA 2006), ela tem uma dimensão intencional que serve para que a discriminação de sexo possa ser melhor explorada no ambiente doméstico e do trabalho remunerado. Para Kergoat (2003, p. 26).

Essa partição dos sexos na produção e na reprodução traduz, então uma divisão sexual, que estrutura assim as relações entre os sexos sobre uma base tanto política quanto econômica. Com efeito, a designação prioritária das mulheres para a reprodução sempre foi acompanhada de sua exclusão do campo sociopolítico.

Assim, em que pese tenha havido maior participação feminina no trabalho produtivo, a divisão sexual das tarefas relacionadas ao trabalho doméstico realizado para 
autoconsumo das famílias não logrou as mesmas transformações. É com base nessa relação, dos usos sociais do tempo de homens e mulheres, que dizemos que a mulher desempenha uma dupla jornada de trabalho. Segundo Ávila (2009, p. 29).

As jornadas de trabalho remunerado e não remunerado que caracterizam a experiência de trabalho da grande maioria das mulheres trabalhadoras produzem uma sobrecarga de trabalho que, no cotidiano afeta a forma de inserção no mercado de trabalho, a participação política cidadã, o lazer, as condições para o estudo e o desenvolvimento da profissionalização, e, ainda, a possibilidade do uso do tempo para si

Nesse sentido, historicamente as análises econômicas praticamente ignoravam o caráter político e social da divisão sexual do trabalho. A tradição neoclássica - mainstream do pensamento econômico - sugeriu, por muito tempo, que as diferenças de gênero nas esferas públicas e privadas derivavam de habilidades naturais adquiridas historicamente. Só a partir de 1980 é que a teoria feminista, conjuntamente com o questionamento das análises econômicas predominantes, impulsionou o campo da Economia Feminista, que se dedica a constituir uma linha de estudos o qual busca concretizar interpretações econômicas levando em consideração a variável gênero e suas implicações. Um dos paradigmas mais importantes das análises da economia feminista é o esforço de visibilizar e demonstrar o valor produzido pelos trabalhos executado pelas mulheres no âmbito privado, o qual, no limite, é fundamental para a sobrevivência do trabalho produtivo (CARRASCO, 2006).

\subsubsection{O avanço da economia feminista no pensamento econômico}

A partir dos anos 1970 a Economia Feminista toma forma, como um desdobramento tanto do avanço das discussões no bojo dos movimentos feministas da segunda onda ${ }^{1}$, no qual viam o problema da opressão das mulheres como uma consequência do poder político e econômico, como também do desenvolvimento de um campo teórico da sociologia que deu corpo ao conceito da divisão sexual do trabalho.

A economia feminista é, ao mesmo tempo, um campo de estudos das ciências econômicas, e um ponto de vista político crítico, ou seja, é uma fermenta de abordagem crítica utilizada por diversos grupos feministas (GRECCO, FURNO \& TEIXEIRA, 2018).

\footnotetext{
${ }^{1}$ As ondas do feminismo são momentos da história que eclodiram movimentos femininos organizados com pautas que se referiam a ampliação dos direitos das mulheres. A primeira onda do feminismo se caracterizava pela reivindicação da ampliação dos direitos civis às mulheres. As "suffragettes" (em português, sufragistas), primeiras ativistas do feminismo no século XIX tinha como bandeira prioritária o sufrágio (o direito de votar).
} 
Dessa maneira, a Economia Feminista não é uma corrente do pensamento econômico, ou seja, ela não se propõe a substituir as abordagens mais tradicionais, tais como a marxista, a marginalista/neoclássica ou a institucionalista, para dar alguns exemplos. Ela é, sobretudo, um campo de estudos que procura não só adicionar, mas problematizar as relações de gênero e questionar o paradigma androcêntrico que subsistem nas diversas correntes teóricas. Ou seja, não é contraditório ser um signatário da economia feminista e ser marxista, por exemplo. Muito pelo contrário, para nós o marxismo é a corrente interpretativa que mais chegou perto de desvendar a opressão sexual pela qual padecem às mulheres, e a relação estreita entre exploração de classe e opressão de gênero.

A economia feminista surge para contribuir na análise de uma problemática que não encontra reflexão nas teorias tradicionais, especialmente as do mainstream econômico. Mesmo as correntes interpretativas que "adicionam" a categoria gênero nas suas análises, são impossibilitadas de desvendar os "porquês", reduzindo-se - apenas - a explicitar uma relação de desigualdade. Para a economia feminista não bastam as estatísticas que diagnostiquem a existência de desigualdades econômicas entre homens e mulheres, senão que as suas premissas sejam explicitadas.

Assim, a economia feminista - comumente - centra uma crítica a dois conjuntos de correntes interpretativas no âmbito das ciências econômicas. A primeira delas - e na nossa opinião, fundamental - é a que faz referência a teoria ortodoxa, conhecida como neoclássica. A estreiteza do foco em métodos matemáticos e econométricos, sem a devida problematização histórica, faz dessa teoria cega no que tange as relações de gênero, que são, sobretudo, relações sociais, o que a faz insuficiente para lograr consistência interpretativa. Além disso, nas raras vezes em que adicionam a problemática de gênero, os marginalistas, ou "ortodoxos" desconsideram a análise histórica.

O principal teórico que refletiu sobre a divisão sexual do trabalho no âmbito dos autores marginalistas foi Becker (1965). O autor utilizou os conceitos da microeconômica para a análise das decisões sociais que competem as famílias. Assim, partido da averiguação de que existem diferenças sociais entre homens e mulheres, o autor oferece como explicação a teoria do capital humano e das decisões racionais. O "homos economicus" é mobilizado para fornecer uma explicação empírica e historicamente frágil. Segundo Becker as famílias são unidades microeconômicas que tomam decisões baseadas na maximização da função utilidade. Assim, é uma decisão racional - pautada na lógica da maximização - que mulheres se dediquem ao trabalho doméstico e os homens 
ao trabalho produtivo. Essas decisões racionais realizadas por mulheres têm explicações na alocação do seu investimento em capital humano, desconsiderando a cultura e história.

Esse olhar sob as famílias e as relações de gênero retira a história como parte da análise, assim como suprime a análise secular das desigualdades de gênero, racionalizando comportamentos que precisam ser compreendidos não de forma individual, senão que inseridos em uma dada sociedade que tem características patriarcais. (GRECCO, FURNO \& TEIXEIRA, 2018, p. 14)

Ainda dentro desse escopo teórico, o processo de valorização do capital é concebido, apenas, dentro da perspectiva que relaciona a valorização ao grau de utilidade do produto e a maximização da satisfação individual. Nesse caso, não somente o trabalho destinado a satisfazer a reprodução social é invisibilizado, quanto todo o processo de trabalho, compreendido como relação social de produção. Trabalhadores, capital, relações sociais de produção são negligenciados e subsumidos em modelos matemáticos que concebem indivíduos sem sexo, fora da história.

Do ponto de vista da crítica às demais correntes econômicas - não somente a ortodoxa/neoclássica - a economia feminista centra esforços na crítica à invisibilidade do trabalho doméstico reprodutivo e sua ausência de conexão fundamental com o produtivo. A ciência economia, comumente, credita valor econômico unicamente aquelas atividades que produzem bens e serviços destinados a troca mercantil. Dessa forma, o conjunto das teorias econômicas acabam se interessando, unicamente, pelo montante dos trabalhos produtivos ou improdutivos - que gerem mais-valia ou valor monetário e estejam plenamente integrados na circulação do capital. Na concepção marxista, somente as mercadorias com "valor de troca" adquirem valor econômico, enquanto o "valor de uso" parece não ser objeto de análise, muito embora ele tenha ligação umbilical com o valor de troca.

A economia feminista advoga a ideia de que todo o trabalho tem valor econômico no modo de produção capitalista, e que ter essa qualidade não significa que ele precise estar na órbita da circulação mercantil. Assim, o trabalho doméstico reprodutivo, aquele que as pessoas realizam cotidianamente para reproduzir a própria vida social, tais como lavar, passar, cuidar dos filhos, cozinhar etc... tem um inestimável valor econômico, embora não seja transacionado no mercado. Nesse sentido, segundo Teixeira (2008) é necessário empreender uma crítica às ciências econômicas pela sua conceituação de "atividade econômica" como somente aquela que gera uma riqueza monetarizada. Assim, o trabalho 
doméstico realizado gratuitamente no interior dos domicílios pelas mulheres não é menos econômico que o assalariado, apenas é de uma natureza distinta.

Essa invisibilidade social do trabalho doméstico tem relação, fundamentalmente, com ele ser exercido pelas mulheres, por excelência, e de forma gratuita. $O$ trabalho doméstico, na medida em que se dedica aos afazeres necessários ao cuidado dos seres humanos, cria as condições para que os trabalhadores possam vender, cotidianamente, a sua força de trabalho no mercado. Ou seja, o trabalho doméstico é o trabalho fundamental para reproduzir a principal mercadoria do modo de produção capitalista, a saber: a força de trabalho humana, a única mercadoria capaz de criar mais valor do que ela vale. Assim, mesmo que invisibilizado socialmente, ele é um dos principais ingredientes para a acumulação ampliada de capital. Mesmo que invisível aos olhos ele permanece no processo de acumulação. "A força de trabalho reproduzida nos lares é entregue ao capital por um valor menor do que de fato vale. Isso oculta, assim, uma enorme quantidade de trabalho realizado pelas mulheres, que passa a formar parte da acumulação contínua do capital." (CARRASCO, 2018, p. 36 e 37).

Para Picchio (2018) a natureza dessa relação fica evidente quando utilizamos a abordagem do excedente para obtenção de lucro. O trabalho doméstico é o trabalho que permite a produção do trabalhador enquanto uma mercadoria, e o trabalho remunerado é a troca do trabalho. Para ocorrer a troca, o trabalho precisa ser produzido; e para que o trabalhado seja produzido é necessário que o trabalhador seja capaz de ser explorado, o que só é possível nas condições de reprodução da sua própria sobrevivência, o que é feito no trabalho doméstico.

Assim, ainda segundo Picchio (2018), não é o trabalho doméstico, apenas, que fica escondido nas concepções que não lançam luz sobre ele, mas sim toda a relação capitalista entre produção e reprodução fica invisibilizada. A economia feminista, dessa forma, concede relevância à relação dialética e necessariamente imbricada entre produção e reprodução social, advogando a tese de que não existe produção sem existir reprodução social.

Quando a relação entre a produção e a reprodução desaparece da análise do contexto econômico, o trabalho concreto de reprodução fica camuflado e as trabalhadoras domésticas se tornam socialmente invisíveis, mesmo que representem uma grande parcela da população de trabalhadores. A economia feminista busca, então

(...) romper o véu da dialética sutil entre a presença real (em nível da atividade concreta) e a ausência simbólica (em nível conceitual) do trabalho 
das mulheres. Para mostrar, igualmente, de que modo as diferenças entre os sexos, ao mesmo tempo, são negadas e exploradas: negadas para serem melhore exploradas. (KARTCHEVSKY et al. 1987, p. 10)

Ainda segundo Carrasco,

A ocultação do trabalho doméstico e de cuidados despolitizou as tensões que têm lugar fora do mercado. Ao naturalizar a divisão sexual do trabalho, consideraram como único conflito social o que tem lugar nos marcos da reprodução capitalista. Por isso que a conceituação do trabalho e da economia feita pelos pensadores clássicos - criticada pela economia feminista - estabelece uma identificação simbólica trabalho-emprego. (CARRASCO, 2018, p. 39)

Antonella Picchio (1994), aponta que para analisar a lógica de continuidade e reprodução do sistema capitalista, é essencial compreender o trabalho realizado nos domicílios gratuitamente pelas mulheres. "A insuficiência teórica que impede que se veja o trabalho de reprodução em termos analíticos deu lugar a uma invisibilidade social deste trabalho e, em certo sentido, das pessoas que o realizam" (TEIXEIRA, 2008, p. 42). Dessa forma, para Picchio (2003), a visibilidade do trabalho doméstico como reivindicação política pretende-se não só explicitar a relação intrínseca existente entre trabalho produtivo/reprodutivo, se não a sua alteração ou um debate mais aprofundado sobre a dinâmica desses trabalhos.

Existe uma invisibilidade do trabalho de reprodução social nas contas nacionais do sistema econômico. A visibilidade do processo do trabalho doméstico requer a visibilidade de uma parte significativa do sistema de reprodução social. A teoria econômica sempre teve uma visão reducionista no que tange ao trabalho de reprodução social. (...) O problema da visibilidade não é só estatístico, mas também teórico e político. (PICCHIO, 2003, p.202 e 203).

Assim, em síntese, a economia feminista tem como proposições fundamentais desvendar a relação intrínseca e necessária existente entre os trabalhos de produção e reprodução social, assim como empreender uma análise crítica no que tange a desnudar a falsa neutralidade das categorias econômicas. Portanto, em linhas gerais, a economia feminista propõe uma ruptura com o paradigma atual das ciências econômicas, não somente quanto a adição da categoria "gênero", mas quanto a sua problematização radical. Isso parte por uma ampliação crítica do que se compreende como "econômico" e a própria noção de trabalho. "Isto é, as economistas feministas não propõem uma simples junção das análises de gênero às teorias predominantes, mas pretendem uma teoria em que as próprias ferramentas analíticas sejam reinventadas". (CARRASCO, 2018, p. 127) 
O desenvolvimento da economia feminista tem como traço, dessa forma, a crítica conceitual e epistemológica da economia dominante, mas - sobretudo - outras críticas e rupturas que ultrapassam a inquietação conceitual, e avançam para se transformar em um posicionamento política.

Ao longo do caminho percorrido nas últimas décadas, a economia feminista se caracterizou por propor rupturas com uma série de conceitos definidos a partir da economia oficial dominante; rupturas que não respondem a uma inquietação conceitual, mas sim a um posicionamento político: faz tempo que aprendemos que a definição e, portanto, a utilização que se faz de determinados conceitos não é neutra, mas apresenta uma grande tendência androcêntrica. Assim, debatemos e reconceituamos os termos trabalho, produção, tempo, cuidados, bem-estar, dependência, reprodução, só para nomear alguns. (CARRASCO, 2018, p. 32)

\section{A economia não é neutra: um olhar para a trajetória de homens e mulheres no mercado de trabalho sob a recessão e a austeridade}

A economia feminista tem tido como preocupação fundamental o desvendamento da neutralidade axiológica das ciências econômicas, referendando a ideia de que as dinâmicas econômicas, além de se desdobrarem das configurações da esfera social, impactam diferentemente os sujeitos. Nesse sentido, a economia feminista tem procurado avançar nas análises de gênero frente às oscilações econômicas, produzido pesquisas com o objetivo de como as transformações, conjunturais e estruturais, se expressam diferencialmente para homens e mulheres. De acordo com Karamessini e Rubery (2014), uma das principais conclusões que se pode observar nos períodos de crise é uma intensificação do trabalho feminino, tanto no âmbito remunerado como não remunerado, condição que é ainda mais aprofundada com a aplicação de políticas de austeridade. Isto porque o Estado tem um papel fundamental na efetivação de políticas que amenizam os aspectos que levam a desigualdade de gênero, tais como o oferecimento de serviços de cuidados, de assistência à criança e demais condições que permitam às mulheres conciliar o trabalho produtivo ao trabalho de cuidados.

A avaliação dos desdobramentos econômicos para os diferentes sujeitos - homens e mulheres - deve levar em consideração as especificidades do desenvolvimento dos países e características específicas da formação socioeconômica, só assim é possível tanto apreender de que maneira as desigualdades de gênero se reproduzem naquele determinado contexto, bem como também avaliar de que maneira as crises tem 
desdobramentos diferenciados frente a distintas características sociohistóricas e econômicas. De acordo com Muñoz \& Madroño, (2011, p. 114),

El estudio de las crisis económicas desde un enfoque de género y, sobre todo, desde la economía feminista, nos permite no sólo analizar los efectos diferenciados que las crisis económicas que se han sucedido en las últimas décadas en varias regiones del mundo o con carácter global, han tenido en mujeres y hombres, sino también complejizar y enriquecer el análisis de las causas de las crisis y sus consecuencias y cuestionar el paradigma macroeconómico ortodoxo predominante en la ciencia económica.

Logo, o ponto de partida da nossa análise reside na ideia de que as condicionantes da atual crise e posteriormente o receituário aplicado pelo Estado brasileiro para conter a recessão impactaram diferencialmente homens e mulheres, fruto das diferenças na posição das mulheres nos setores produtivos, na esfera doméstica e das normais sociais vigentes sobre os papéis de gênero.

\subsection{Crescimento econômico e estruturação do mercado de trabalho: primeira década dos anos 2000}

Antes de adentrar na caracterização da crise e das opções de política econômica que lograram a saída via austeridade, convém retomar - brevemente - as principais características do ciclo anterior, tanto do ponto de vista macroeconômico mais geral, como das transformações transcorridas no mercado de trabalho.

A primeira década dos "anos 2000" é analisada, por nós, a partir de um recorte que é - sobretudo - político. Compreendemos, assim, os anos 2000 como o período que vai da assunção de Luiz Inácio Lula da Silva à Presidência da República, em 2003, até o fim do primeiro mandato da Presidente Dilma Rousseff no ano de 2014. Nesses anos o país experimentou uma trajetória de crescimento econômico aliado a políticas de redução de desigualdade social e de regulação sob o mercado de trabalho.

Os governos petistas, nesse período, foram guiados por um projeto de desenvolvimento que, por um lado, abandonou parte do receituário neoliberal da década anterior, com maior intervenção do Estado no que o papel das empresas estatais, o freio as privatizações e, sobretudo, o aumento no volume do gasto social do Estado. Por outro lado, mantém vigente - as vezes até radicalizando-o - o chamado "tripé macroeconômico", o qual - ao manter-se fidedigno as metas de inflação, ao câmbio flutuante e ao superávit fiscal - por vezes foi um bloqueador do desenvolvimento nacional, impondo constrangimentos à política fiscal e ao controle cambial. 
É inegável que a performance da economia brasileira, nesse período, não se explica - somente - por condicionantes endógenos. A maior liquidez da economia mundial e a melhora nos termos de troca jogou um papel importante no equacionamento do que outrora foi nosso principal gargalho, a saber: a restrição externa. Assim, faz-se importante jogar luz ao processo da valorização das commodities comercializadas pelo Brasil no mercado internacional, assim como a vinda de capitais externos de forma suficiente a fechar o balanço de pagamento brasileiro (ROSSI \& MELLO, 2016). Por outro lado, o ciclo dos governos petistas não pode ser passível de cair à análise superficial de que somente o mercado externo explica nossa performance recente. A singularidade desse período foi que o maior crescimento econômico do período - ainda que tímido levando em considerações períodos passados - foi acompanhando de políticas públicas destinadas a redução das desigualdades sociais, de formalização do mercado de trabalho e de expansão do mercado de consumo interno (FURNO, 2016).

Segundo Fagnani (2011) é a conjugação de estabilidade econômica, crescimento, distribuição de renda e inclusão social que explicou o desenvolvimento social dos anos 2000. Para o autor, o principal mérito dos governos petistas foi construir uma estratégia macroeconômica conjugando desenvolvimento social ancorado no crescimento, com reflexos na geração de emprego, valorização do salário mínimo, aumento do gasto social e no incentivo às políticas universais e de combate à pobreza.

Do ponto de vista do mercado de trabalho, a sua reativação em uma trajetória de formalização foi um dos principais determinantes da relativa melhora na condição socioeconômica da população brasileira (BALTAR, 2015). Demasiados foram os efeitos positivos sobre o mercado de trabalho promovidos pela estratégia de desenvolvimento pautada no crescimento econômico e na centralidade do emprego (FURNO, 2016).

Um dos principais feitos desse período foi ter reduzido drasticamente o contingente de desempregados no país, que nos anos 90 atingiu taxas exorbitantes. Não somente o desemprego diminuiu como se expandiu o emprego formal. Segundo Baltar et al (2010) houve crescimento do emprego nos setores mais organizados da economia, inclusive na grande empresa e no setor público. A contrapartida foi a perda do peso do trabalho assalariado sem registro, e também do trabalho por conta própria. O trabalho doméstico também vivenciou um período de queda absoluta e percentual nesse período, o que atesta uma melhora na composição das ocupações na força de trabalho (FURNO, 2016).

Além disso, outro ponto central, sem dúvida, para a melhoria os indicadores do mercado de trabalho foi a progressiva valorização do salário mínimo, principalmente para 
os trabalhadores mais pobres, que veem seu rendimento valorizar anualmente, indexado no piso salarial mínimo. De 2003 até 2014, o salário mínimo nacional teve ganho real de $70 \%$ (ROSSI \& MELLO, 2014). A informalidade passou de $57 \%$ do total da força de trabalho, em 2002 para 46\% em 2014. Ainda que esse dado ateste a profunda desproteção do mercado de trabalho brasileiro, a sua queda se insere nessa estratégia de crescimento econômico com melhorias sociais, notavelmente no mercado de trabalho (ROSSI \& MELLO, 2014).

O período entre 2004 e 2013 atestou substantivas melhoras para mulheres. Houve um aumento 5,11 milhões de mulheres na PEA, além de serem absorvidas 5,92 milhões de mulheres ao mercado de trabalho e formalizadas mais 5,81 milhões, ou seja, houve uma absorção tanto das novas ingressantes como as das desempregas. Segundo Teixeira (2017, p. 174),

\begin{abstract}
A população ocupada também apresentou resultados positivos, passando de $42,1 \%$ para $42,7 \%$ sinalizando para uma incorporação na atividade econômica das mulheres que se colocaram no mercado de trabalho e absorvendo parte do desemprego: foram 5,918 milhões de mulheres e 6,809 milhões de homens. Desta forma, a população ocupada evoluiu $17,0 \%$ e $14,0 \%$, respectivamente, para mulheres e homens. (...) Entre 2004 e 2013 o desemprego para as mulheres recuou $17,8 \%$. Contudo, entre os homens, o percentual foi idêntico, $18,2 \%$, contribuindo, dessa forma, para que as mulheres continuassem sustentando as maiores taxas de desemprego mesmo em um período mais favorável. Elas passaram de $11,5 \%$, para $8,4 \%$, já entre os homens a queda foi de $6,6 \%$ para $4,8 \%$ entre 2004 e 2013 . As taxas de desemprego das mulheres são persistentes e representam o dobro da masculina, independentemente dos ciclos econômicos.
\end{abstract}

Ou seja, ainda que a desigualdade entre homens e mulheres são tenha superado a barreira estrutural que a fundamenta, características econômicas e políticas desse período representam avanços significativos para a vida e as condições de trabalho das mulheres. Um elemento fundamental foi a melhora nos rendimentos das mulheres em comparação com os rendimentos dos homens, consequência direta da política de valorização do salário mínimo. Esta política beneficiou, sobretudo, os trabalhadores da base da pirâmide salarial que são constituídos, majoritariamente, de mulheres. Em 2004 as mulheres recebiam, em média, $69,5 \%$ e avançaram para $73,1 \%$ do rendimento médio dos homens, diminuindo a diferença salarial entre os sexos.

Nesse sentido, o chamado "Anos 2000" possibilitou uma melhoria nas condições gerais do mercado de trabalho, resultado de uma conjugação de fatores que envolveram maior dinamismo e crescimento econômico, atuação do Estado e inclusão social. Contudo 
a partir de 2015 a economia brasileira é assolada por uma grave crise econômica que redefini o papel do Estado e impõe um novo arranjo econômico e político-institucional.

\subsection{0 trabalho feminino frente a recessão econômica}

Desde o final de 2014 a economia brasileira vive uma inflexão na trajetória econômica estabelecida até então. Consolida-se uma desaceleração do crescimento, resultado de uma combinação de fatores da conjuntura econômica internacional, como a diminuição da demanda e queda dos preços das comodities, e da conjuntura interna, como a queda da taxa dos investimentos, a queda da arrecadação e o somatório de uma crise política que contribuiu no aumento das incertezas.

Para compreender a natureza da crise no Brasil é preciso olhar, primeiramente, para o contexto internacional, pois o Brasil - assim como os demais países da América Latina é conhecido por ser uma economia mais vulnerável e dependente das oscilações da economia internacional, comportamento típico de economias dependentes e subdesenvolvidas, que tem sua base econômica - prioritariamente - pautada nas exportações, sobretudo de produtos primários. Nesse sentido, a atual crise econômica que tem dimensões globais e impacta mais fortemente as economias dependentes. Assim, desde 2014, há um profundo desaquecimento do comércio internacional, devido à persistente baixa da demanda dos países centrais que, aliado a queda dos preços dos commodities, impactou diretamente as taxas de crescimento do PIB brasileiro. As exportações declinaram 12,0\% em 2014, comparativamente a 2011, enquanto as importações aumentaram $1,2 \%$ prejudicando a balança comercial bem como o ciclo de liquidez interno que subsidiou as políticas que contribuíram com dinamismo econômico dos anos 2000 no Brasil.

Outro elemento que corroborou para consolidar essa inflexão econômica no período foi a queda na taxa de investimento. Conforme dados das contas nacionais (2016), a formação bruta de capital fixo (FBCF), que chegou em 2008 a representar mais de $20 \%$ do PIB, em 2013 cai para menos de 18\%. De acordo com a nota do Centro de conjuntura da Unicamp (2017), em 2015 os investimentos públicos sofreram queda real de mais de 40\% no nível federal.

Destaca-se que o orçamento de investimento das Estatais Federais (onde a Petrobrás é responsável por quase $85 \%$ ) apresentou sucessivas quedas a 
partir de 2013, quando o orçamento de investimento executado foi de R\$ 113 bilhões, passando para 95,5, 80,2 e 56,5 bilhões de reais respectivamente em 2014, 2015 e 2016. (2017, p. 2)

Rapidamente estes resultados se desdobaram para o mercado de trabalho, de acordo com os dados da PNADC, o desemprego praticamente dobrou em dois anos, passando de 6,4\% em dezembro de 2014 para 12\% em dezembro de 2016, o maior índice de desocupação das últimas décadas. O aumento do desemprego foi causado, principalmente, pela queda da população ocupada (PO), ocasionado - sobretudo - pela extinção de postos de trabalho, consequência direta da queda da taxa de atividade econômica. Quando analisamos a taxa de desocupação por gênero percebemos que ela cresce entre homens e mulheres, como demonstra o gráfico 1.

Gráfico 1 - Taxa de desocupação na semana de referência para pessoas de 14 anos ou mais de idade por sexo entre 2012 e 2018

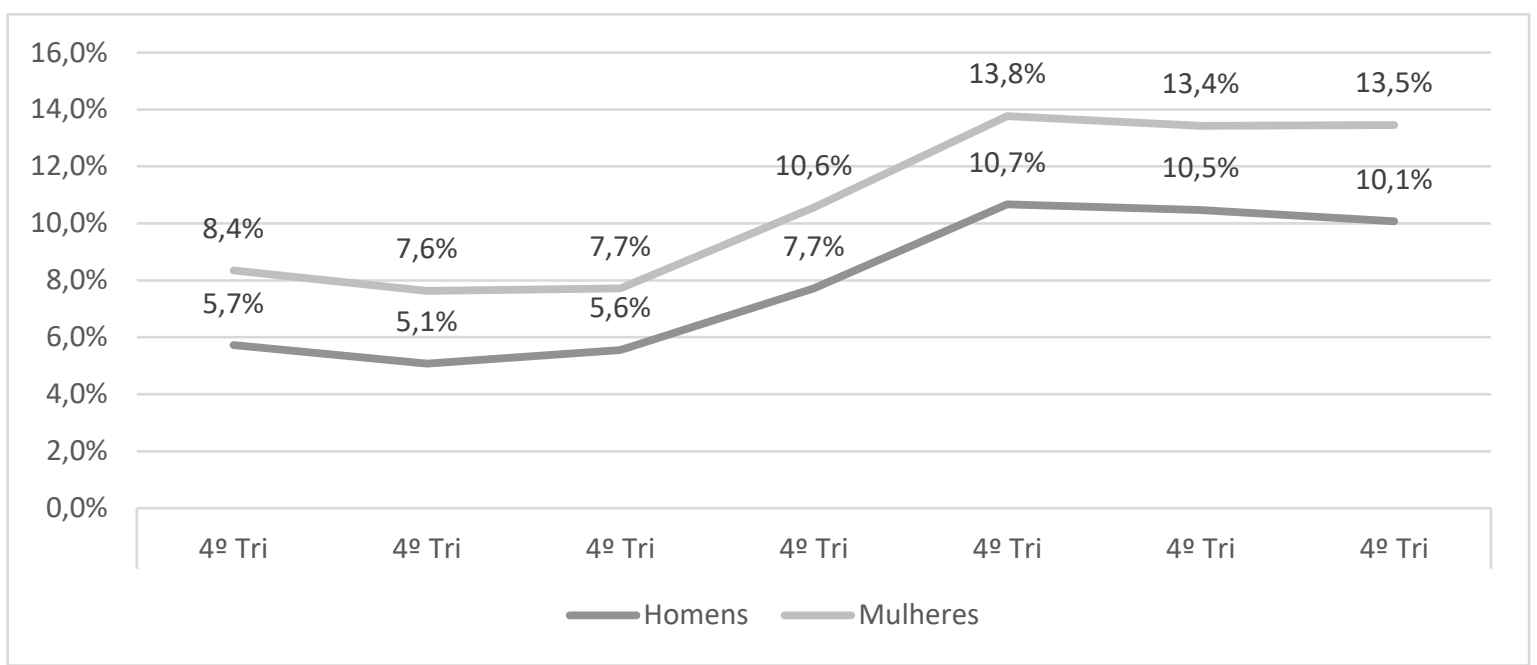

Fonte: IBGE/PNAD. Elaboração Própria

A subtração de postos de trabalho deduzidas da queda da atividade econômica manifestou-se em grupos estratégicos que lograram forte crescimento nos anos 2000, como o setor da Agropecuária, Indústria, Construção e Administração pública. De acordo com a tabela 1 é possível verificar que os três grandes grupos de atividade econômica (Agropecuário, Indústria e Construção) sofreram forte retração no número de pessoas ocupadas, a agropecuária sofreu uma variação de -14,91\% entre 2012-2016, e a Indústria e a Construção de $-13,83 \%$ e $-3,05 \%$ respectivamente.

Tabela 1 - Pessoas de 16 anos ou mais de idade ocupadas no trabalho principal, segundo os setores de atividades Brasil - 2012-2016 


\begin{tabular}{l|c|c|c|c|c|c}
\hline \multicolumn{1}{c|}{$\begin{array}{c}\text { Setores de } \\
\text { atividades }\end{array}$} & $\mathbf{2 0 1 2}$ & $\mathbf{2 0 1 3}$ & $\mathbf{2 0 1 4}$ & $\mathbf{2 0 1 5}$ & $\mathbf{2 0 1 6}$ & $\begin{array}{c}\text { Variação } \\
\mathbf{2 0 1 2 / 2 0 1 6}\end{array}$ \\
\hline Agropecuária & $11,4 \%$ & $11,1 \%$ & $10,4 \%$ & $10,11 \%$ & $9,93 \%$ & $-14,91 \%$ \\
\hline Indústria & $14,4 \%$ & $14,0 \%$ & $14,4 \%$ & $13,87 \%$ & $12,63 \%$ & $-13,83 \%$ \\
\hline Construção & $8,4 \%$ & $8,8 \%$ & $8,4 \%$ & $8,30 \%$ & $8,17 \%$ & $-3,05 \%$ \\
\hline $\begin{array}{l}\text { Comércio } \\
\text { Reparação }\end{array}$ & $18,8 \%$ & $18,9 \%$ & $18,8 \%$ & $19,03 \%$ & $19,17 \%$ & $1,79 \%$ \\
\hline $\begin{array}{l}\text { Administração } \\
\text { pública }\end{array}$ & $6,6 \%$ & $6,5 \%$ & $6,3 \%$ & $5,84 \%$ & $5,66 \%$ & $-15,79 \%$ \\
\hline $\begin{array}{l}\text { Educação, saúde } \\
\text { e serviços sociais }\end{array}$ & $9,6 \%$ & $9,6 \%$ & $10,2 \%$ & $10,88 \%$ & $11,58 \%$ & $17,45 \%$ \\
\hline $\begin{array}{l}\text { Serviços } \\
\text { domésticos }\end{array}$ & $6,9 \%$ & $6,7 \%$ & $6,5 \%$ & $6,64 \%$ & $6,86 \%$ & $-0,68 \%$ \\
\hline Demais serviços & $23,9 \%$ & $24,5 \%$ & $24,9 \%$ & $25,31 \%$ & $25,99 \%$ & $8,09 \%$ \\
\hline Total & $\mathbf{1 0 0 \%}$ & $\mathbf{1 0 0} \%$ & $\mathbf{1 0 0 \%}$ & $\mathbf{1 0 0 \%}$ & $\mathbf{1 0 0 \%}$ & $\mathbf{0}$ \\
\hline
\end{tabular}

Fonte: IBGE/PNAD. Elaboração Própria

Os setores econômicos mais afetados pela atual crise econômica são, historicamente, conhecidos por deter forte alocação de mão de obra masculina. Segundo os dados do IBGE em 2015 - que representa o início da reversão dos indicadores no mercado de trabalho - os homens ocupavam $79 \%$ dos postos de trabalho na Agropecuária; $96,6 \%$ na Construção e $66 \%$ na Indústria. Assim, ainda que as taxas de desocupação tenham aumentado para homens e mulheres, ela foi proporcionalmente maior entre os homens.

Quando olhamos mais atentamente as taxas de participação, ocupação e desemprego por gênero, constatamos que o desemprego entre os homens ocorre pela diminuição do número de ocupados, sinalizando uma retração da população masculina ocupada. Já o aumento da taxa de desocupação entre mulheres manifesta-se mais em função do aumento da taxa de participação, ou seja, pelo aumento do número de mulheres na população economicamente ativa que passam a buscar emprego no período de crise. As mulheres, portanto, tem uma elevação na taxa de desocupação pela inserção de mais mulheres na força de trabalho que não foram absorvidas, como demonstra a tabela 2.

\begin{tabular}{l|l|l|c|c|c|c}
\hline & \multicolumn{2}{|c|}{ Taxas de participação } & \multicolumn{2}{c|}{ Taxas de Desemprego } & \multicolumn{2}{c}{ Taxas de ocupação } \\
& $\mathbf{2 0 1 4}$ & $\mathbf{2 0 1 6}$ & $\mathbf{2 0 1 4}$ & $\mathbf{2 0 1 6}$ & $\mathbf{2 0 1 4}$ & $\mathbf{2 0 1 6}$ \\
\hline
\end{tabular}




\begin{tabular}{l|r|r|r|r|r|r}
\hline Homens & 72,2 & 72 & 5,6 & 10,7 & 68,2 & 54 \\
\hline Mulheres & 50,6 & 51,6 & 7,7 & 13,8 & 46,7 & 44,5 \\
\hline Total & 60,9 & 61,4 & 6,5 & 12 & 56,9 & 54 \\
\hline
\end{tabular}

Tabela 2 - Condição de Atividade por sexo. Brasil entre 2014 e 2016 ( $4^{\circ}$ trimestre)

Fonte: IBGE - PNADC. Elaboração Própria.

Quando olhamos para os dados desagregados por setores podemos observar o viés de gênero fortemente impregnado na composição da força de trabalho dos setores. Isto porque os papéis de gênero são construídos sob a ideia de que existem características eminentes aos sexos, e que isso possibilita melhor performance em determinadas tarefas, conformando o que chamamos de "trabalho de homem" e "trabalho de mulher". Nesse sentido, uma primeira explicação para estes dados, é de que a segmentação do mercado de trabalho por gênero acabou por proteger, num primeiro momento, o emprego feminino na crise, justamente por ter afetado os empregos mais tradicionais, sobretudo os ligados à indústria, onde - por naturalização da divisão sexual do trabalho - não estão as mulheres. Ou seja, a natureza da crise deteriorou os postos de trabalho que incorporam mais mão de obra masculina (HIRATA, 2015).

O aumento do número de mulheres em busca de trabalho pode estar relacionado com a extinção dos postos de trabalho ocupados pelos homens. Isto porque, diante da perda do emprego masculino, muitas mulheres passaram a buscar uma oportunidade de trabalho, com o objetivo de manter a renda da família, que antes eram garantidas pelo homem. As mulheres, portanto, compõe o chamado "trabalhador adicional" (LUNDBERG, 1981).

Segundo Lundberg (1981), o trabalhador adicional aparece, sobretudo, nas economias em depressão, nas famílias cujos membros empregados perdem seus empregos e, diante disto, para compensar a queda na renda familiar, outros membros da família - os trabalhadores secundários - passam a fazer parte da força de trabalho. Estudos apontam que o trabalhador adicional é protagonizado fundamentalmente pelas mulheres, corroborando com o ideário social do marido como provedor natural do lar. (FERNANDES, \& FELÍCIO, 2002).

Ainda nesse sentido, segundo Rubery (2014), as empresas em períodos de recessão repensam os seus custos e veem na desvalorização da mão de obra feminina uma possibilidade de otimizarem suas taxas de lucro, o que pode explicar a manutenção e a 
maior contratação de mulheres nos setores historicamente masculinizados, justamente pelas condições usuais de empregabilidade das mulheres.

Outra forte característica de momento de períodos de recessão é o crescimento do setor informal frente ao formal. Tal como analisado nos chamados "anos 2000" houve crescimento contínuo do setor formal. No entanto, a partir do início de 2015 essa tendência se reverte. Com relação a formalização do trabalho, os dados nos mostram que a taxa da população ocupada com carteira assinada retrocedeu nos últimos anos, em 2013 essa categoria apresentava um total de 53\% dos trabalhadores totais caindo em 2017 para 50\%. $\mathrm{Na}$ análise dos dados segundo o sexo, dentre os trabalhadores formalizados, homens e mulheres passam a deter taxas bastante equiparadas, essa equiparação ocorre, principalmente, pela queda do número de "empregados com carteira assinada no setor privado" entre os homens, que em 2014 era de 42\% caindo em 2017 para 38\%, nesse período as mulheres eram $33 \%$ desta categoria.

Contudo, quando olhamos os dados de posição da ocupação agregados - como mostra o gráfico 2, a taxa de informalidade para as mulheres vem crescendo desde 2016, chegando em 2017 a $48 \%$ do total de mulheres ocupadas, principalmente em decorrência do aumento dos chamados "conta-própria", ou seja, mulheres que fazem bicos. O que demonstra que as mulheres se inserem no mercado de trabalho no período de crise em postos de trabalho à margem da legislação trabalhista. No gráfico abaixo é possível comparar a parcela da população ocupada na informalidade com o total de ocupados por sexo, os homens acabam por deter maiores taxas justamente por serem a maior população ocupada, mas proporcionalmente, quando desagregado por sexo, as mulheres ocupadas estão fortemente alocadas na informalidade. 
Gráfico 2 - Total de pessoas ocupadas e o total de informais, para pessoas de 14 anos ou mais de idade, exclusive empregadores, por sexo (Brasil, 2012 a 2018)

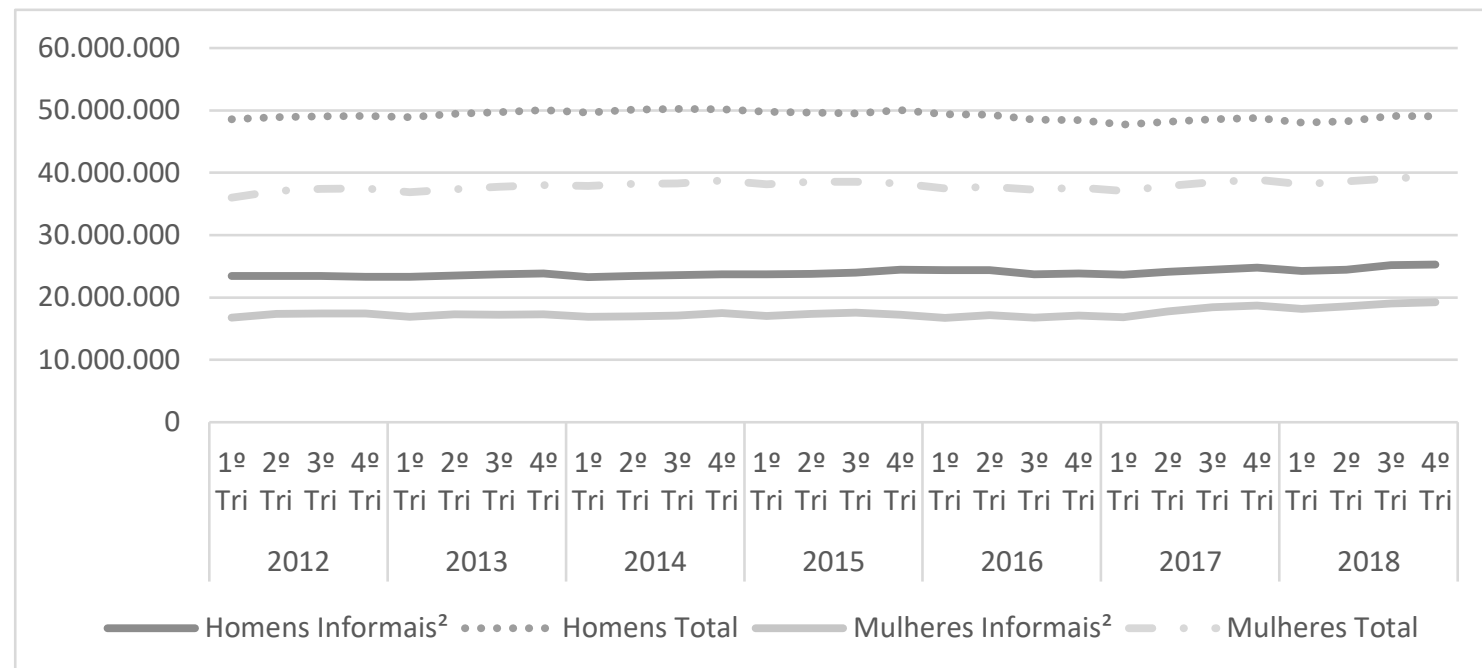

Fonte: IBGE/PNADC; Elaboração própria.

Hirata e Humprhey (1989) ao analisarem o processo de crise econômica dos anos 1980 e a corrosão dos empregos industriais - que são os mais protegidos no que se refere a legislação trabalhista - identificaram que o trabalho doméstico foi a possibilidade de sobrevivência para um grande contingente de mulheres que foram mantidas alijadas do trabalho formal - bem como a expulsão de seus cônjuges - ou uma possibilidade de trabalho mediante a segregação de setores historicamente ocupado por homens. Segundo Bruschini e Lombardi (2000), o trabalho doméstico é um gueto feminino no mercado de trabalho, e tem sido uma "oportunidade" histórica de inserção das mulheres no mercado de trabalho, mas que segue reproduzindo condições de trabalho muita precárias. O gráfico 3 nos mostra que no início de 2015 ocorre um aumento no percentual de mulheres ocupadas no emprego doméstico no Brasil. 
Gráfico 3 - Percentual de mulheres ocupadas no serviço domésticos na semana de referência para pessoas de 14 anos ou mais de idade entre 2012 e 2018

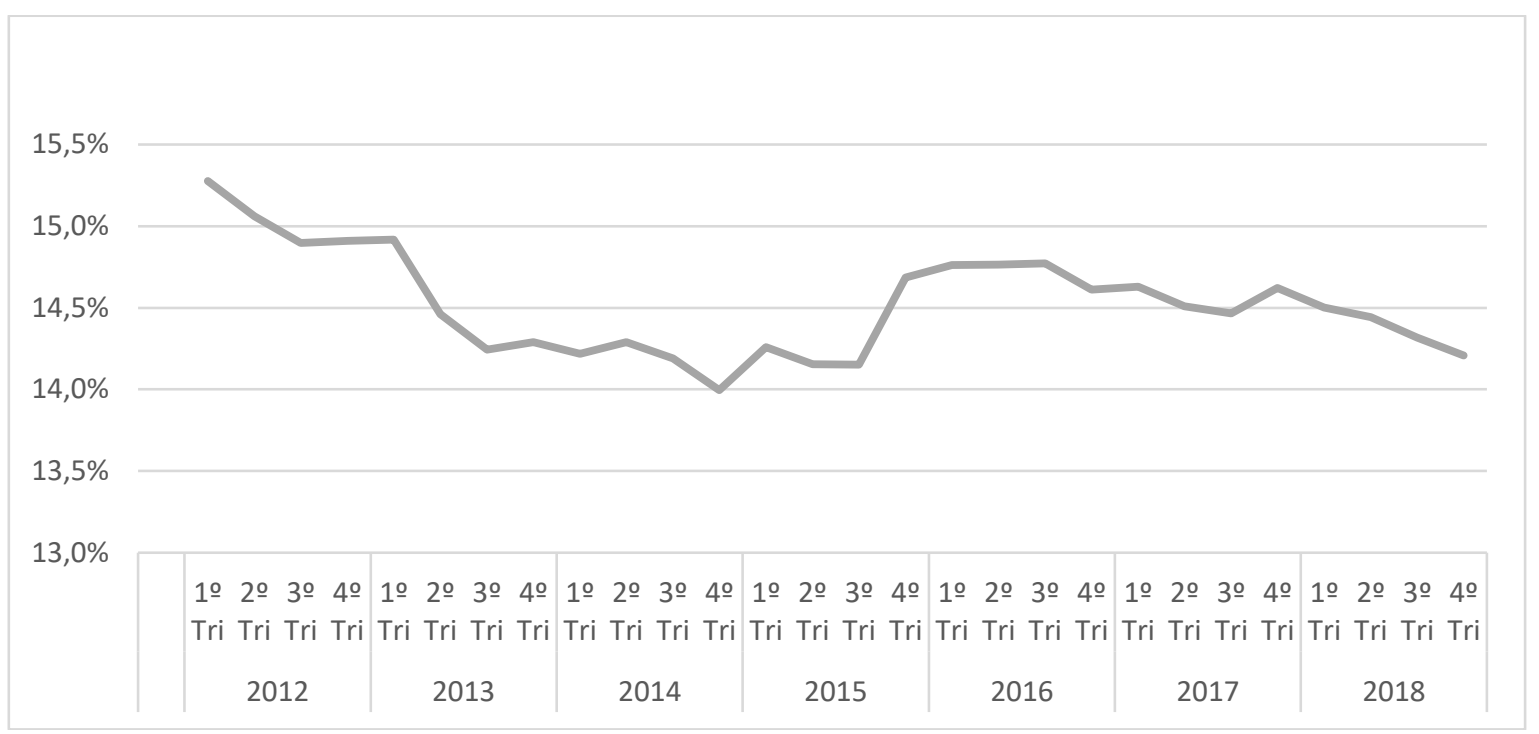

Fonte: IBGE/PNAD. Elaboração Própria

Olhando esse gráfico é possível identificar que no início da crise (2015) há um boom na taxa de ocupação em serviço doméstico, mas que vem caindo com o passar dos anos, isto por ser explicado pela continuidade dos aspectos recessivos na economia brasileira, muito em função das políticas adotadas para conter a crise (VIECELI, FURNO \& HORN, 2017).

Assim, diante da análise dos dados é possível observar, nos primeiros dois anos da recessão econômica, a intensificação do trabalho feminino na esfera produtiva, sobretudo em função da extinção de postos de trabalho nos setores historicamente masculinizados. Nesse sentido há uma diminuição do gap entre homens e mulheres referente as taxas de desocupação, mas em função de uma deterioração geral dos termos do mercado de trabalho. Esse cenário toma outras modulações diante da aplicação de políticas de austeridades adotadas pelo governo brasileiro em meados de 2015.

No Brasil, o diagnóstico das causas da crise repousou, prioritariamente, na ideia do descontrole dos gastos, ou seja, de que os crescentes déficits do orçamento eram consequência do aumento "exagerado" dos gastos públicos, sobretudo com as políticas sociais (MELLO, 2015). Portanto, como já mencionado, a solução adotada foi a de redução e corte do orçamento destinado as despesas primarias, que englobam as políticas sociais, prioritariamente. 


\subsection{O trabalho feminino frente a austeridade}

Políticas de austeridade em uma economia já fragilizada tendem a acarretar em choques recessivos e na necessidade de mais ajustes, que se tornam um processo contínuo e desencadeiam uma espiral recessiva (MELLO, 2015). No Brasil, na nossa opinão, essa opção acabou aprofundando ainda mais os elementos da crise. Num país que possui um alto contingente de população em situação de vulnerabilidade social, dependente de políticas públicas e sociais, a diminuição do papel do Estado acaba por deteriorar ainda mais os problemas estruturais da nação.

O principal objetivo da adoção de um ajuste fiscal foi recuperar a confiança dos agentes que retornariam a investir ao constatar que o Estado tinha suas contas controladas, por reduzir suas das despesas públicas, atendendo a lógica ortodoxa de política fiscal das finanças públicas sadias. Para esse propósito, o governo estabeleceu uma meta inicial de superávit primário de $1,2 \%$ do PIB, e implementou um conjunto de medidas para reduzir os gastos públicos.

A austeridade econômica tem uma dimensão política, e afeta de forma distinta os diferentes agentes econômicos e classes sociais, de forma que os mais vulneráveis, que mais dependem de políticas sociais e fazem mais uso dos serviços públicos, são mais afetados. Segundo Millios (2015) a austeridade visa justamente dar respostas a um conflito distributivo entre as frações de classe, uma vez que além de direcionar a política econômica para a proteção dos interesses capitalistas também fortalece a esfera privada de oferta de serviços essências como saúde e educação.

Essa opção política de tentativa de retomada do crescimento pela opção da austeridade teve um impacto mais significativo para as mulheres, isto porque elas são as mais dependentes das políticas sociais (TEIXEIRA, 2018). A responsabilização das mulheres pela efetuação das tarefas domésticas e de cuidados impõe limites à sua inserção no mercado de trabalho. É a partir dessa realidade que percebemos a importância do papel no Estado na efetivação de políticas e programas que deem respostas a esta demanda social, constituindo equipamentos públicos que socializem as tarefas exercidas no âmbito doméstico, como creches e escolas de tempo integral, bem como a ampliação de políticas de transferência de renda que possibilitem tanto o aumento do tempo disponível das mulheres quanto a sua autonomia econômica. 
Segundo os dados do Cadastro Único, órgão do Ministério do Desenvolvimento Social, em 2014 o percentual de mulheres chefiando domicílios que recebiam os benefícios do Programa Bolsa Família era 93\%, ou quase 13 milhões de famílias. Contudo entre 2014 e 2018 há uma variação de $-16 \%$ do orçamento destinado a esta política, havendo uma diminuição da cobertura deste benefício. Isso contribui para o aprofundamento das condições de pobreza do conjunto das famílias dependentes desse benefício.

Outra política de suma importância que é desmontada pós 2015 é a política de valorização do salário mínimo que teve efeitos especialmente positivos para as mulheres. Para mais de 12 milhões de mulheres, notadamente as trabalhadoras domésticas, reduziuse o fosso salarial que separa os seus rendimentos do dos homens. De acordo com os dados do IBGE, o rendimento médio nominal entre as mulheres menos escolarizadas cresceu $183 \%$, entre 2004 e 2014 . Para aquelas com maior escolaridade, foi de $94 \%$. Todo esse conjunto de ações estimula a elevação dos pisos salariais, e impacta positivamente a distribuição de renda, reduzindo as desigualdades de gênero. Contudo, entre 2017 e 2018 o salário mínimo passou a ser ajustado somente pelo índice inflacionário (IPCA), desmontando as características de elevação do ganho real.

A política educacional nos anos 2000 também logrou resultados positivos com a ampliação de creches e escolas de tempo integral, o acesso a creche teve um expressivo aumento. Segundo o relatório "Educação para todos 2001 - 2015" do Ministério da Educação, em 2001, apenas 10,6\% das crianças entre 0 a 3 anos estavam matriculadas na educação infantil, em 2013 este percentual sobe para 23,2\%. Embora seja um resultado ainda aquém das demandas reais, a proposta do governo era a universalização, até 2016, da educação infantil através do Plano Nacional de Educação (PNE, Lei no 13.005/2014). Já as matriculas em escolas de tempo integral triplicaram desde 2010, alcançando 3,1 milhões de crianças e adolescentes em 2014. Ou seja, esse conjunto de políticas permitem uma maior autonomia das mulheres frente aos cuidados com os filhos e, portanto, melhores condições de se inserirem no mercado de trabalho. A partir de 2014 há uma tendência de reversão deste quadro. O gráfico 1 mostra com clareza a drástica redução do orçamento para esta área, que praticamente elimina recursos para este setor. A implicação direta disto é a diminuição do número de vagas e, portanto, o deslocamento para esfera doméstica do cuidado das crianças. 
Gráfico 4 - Educação infantil no orçamento efetivo da União (em reais)

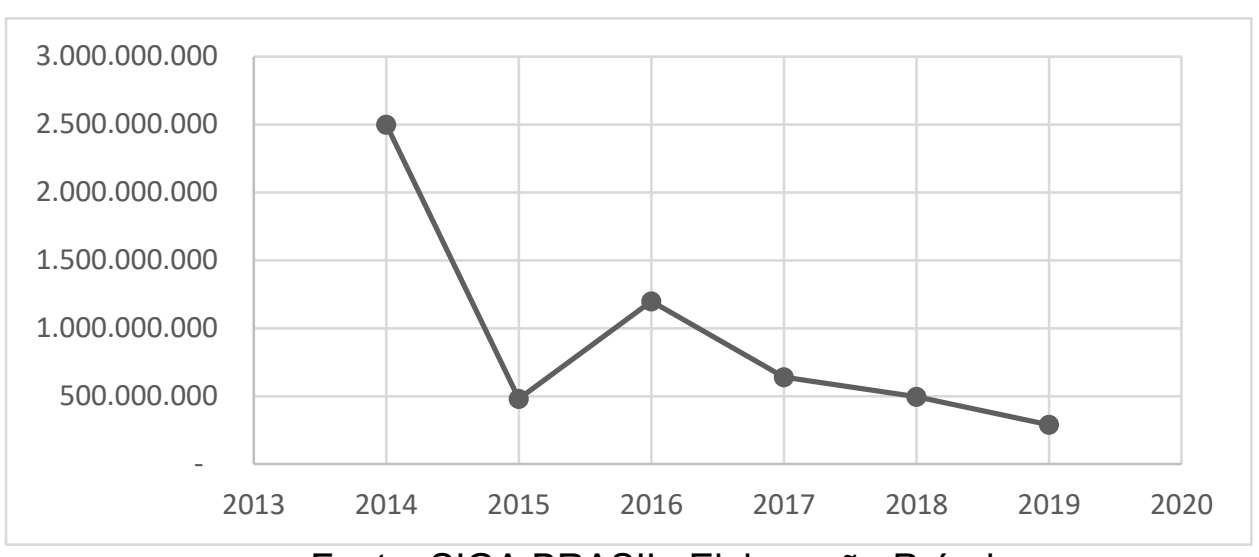

Fonte: SIGA BRASIL. Elaboração Própria.

Quando olhamos os desdobramentos destas medidas no mercado de trabalho brasileiro, elas nos permitem, de antemão, afirmar que a trajetória das mulheres nesta esfera - a despeito dos processos de dinamismo econômicos vividos no início dos anos 2000 - acaba por retroceder em níveis anteriores a este período. Segundo Teixeira (2014, p.16), "em uma sociedade desigual e capitalista [as desigualdades de gênero] não se superam apenas por ação do crescimento da atividade e econômica e pela ampliação do mercado de trabalho". Nesse sentido, o desmonte de políticas públicas direcionadas aos cuidados aumenta o montante de trabalho efetuado na esfera doméstica, que é, historicamente, designado às mulheres.

A subocupação se refere aos sujeitos que trabalham um número insuficientes de horas semanais, ou seja, número abaixo do considerado para estar plenamente ocupado na esfera produtiva. Como podemos observar no gráfico 6, a partir do final de 2015 este tipo de situação cresce bastante entre as mulheres. 
Gráfico 5 - Subocupação por insuficiência de horas trabalhadas para pessoas de 14 anos ou mais de idade por sexo entre 2012 e 2018

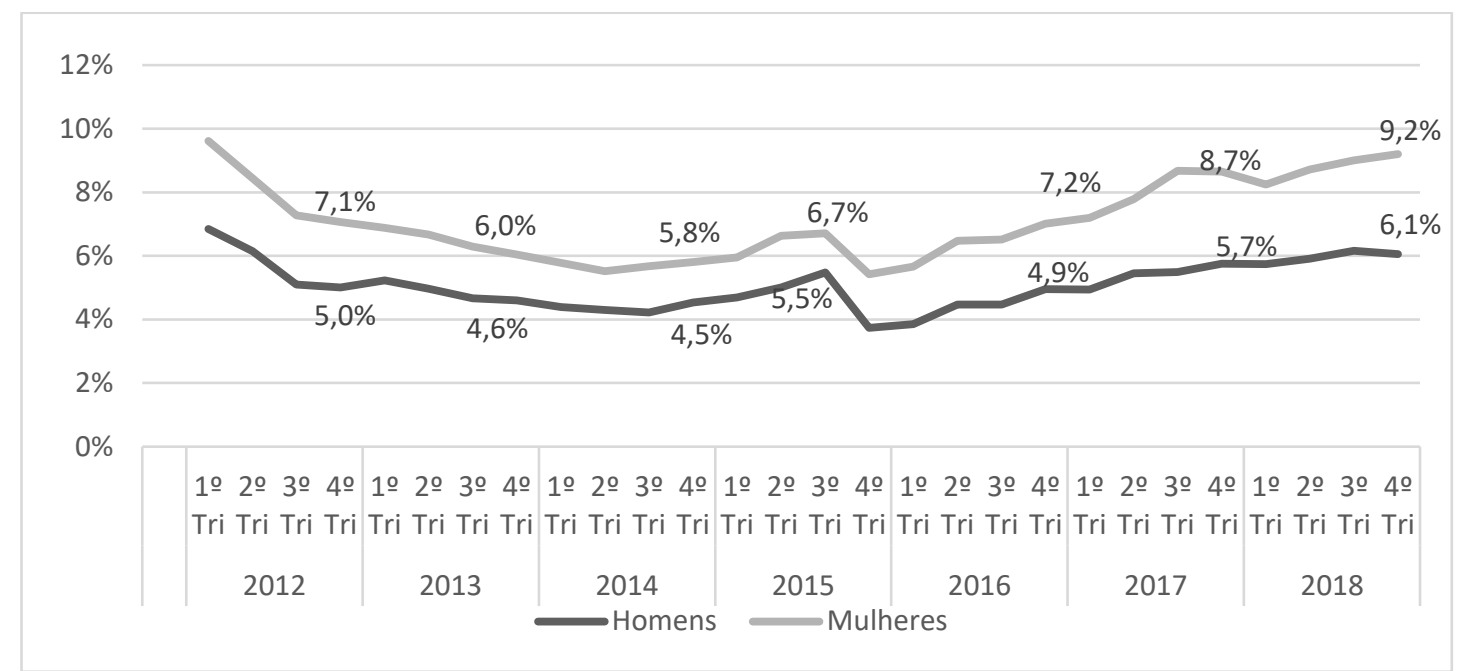

Fonte: IBGE/PNAD. Elaboração Própria

Uma das possíveis causas para a elevação da subocupação das mulheres é justamente o aprofundamento das tarefas do âmbito doméstico, ou seja, um aumento da carga de trabalho na esfera doméstica que faz com que as mulheres tenham que se inserir no mercado de trabalho em empregos que possibilitem a conciliação entre as obrigações no âmbito doméstico e no mercado de trabalho. A necessidade de conciliação entre as tarefas domésticas e no mercado de trabalho tem sido um dos maiores condicionante da inserção das mulheres no mercado de trabalho, configurando o que chamamos de dupla jornada de trabalho. De acordo com Freitas (2016) alguns setores que são segmentados por gênero, como o teleatendimento, se apropriam destas condições de inserção feminina no mercado de trabalho, ofertando formas flexíveis de contratação, evidentemente dentro de um movimento geral do desenvolvimento do capitalismo contemporâneo, mas que deixa claro como este processo de reestruturação recente se vale de formas de exploração que tem o gênero como marcador.

Para corroborar com esta hipótese um indicador que nos ajuda a situar em que medida as condições de precarização do emprego feminino se aprofundam pós-2015, é o dado sobre subutilização da força de trabalho. A subutilização é a taxa que compreende a Força de trabalho potencial - os que estão em idade ativa, mas não estão procurando emprego-, os desocupados e os subocupados por insuficiência de horas de trabalho. 
Gráfico 6 - Subutilização da força de trabalho para pessoas de 14 anos ou mais de idade por sexo (Brasil, 2012 a 2018)

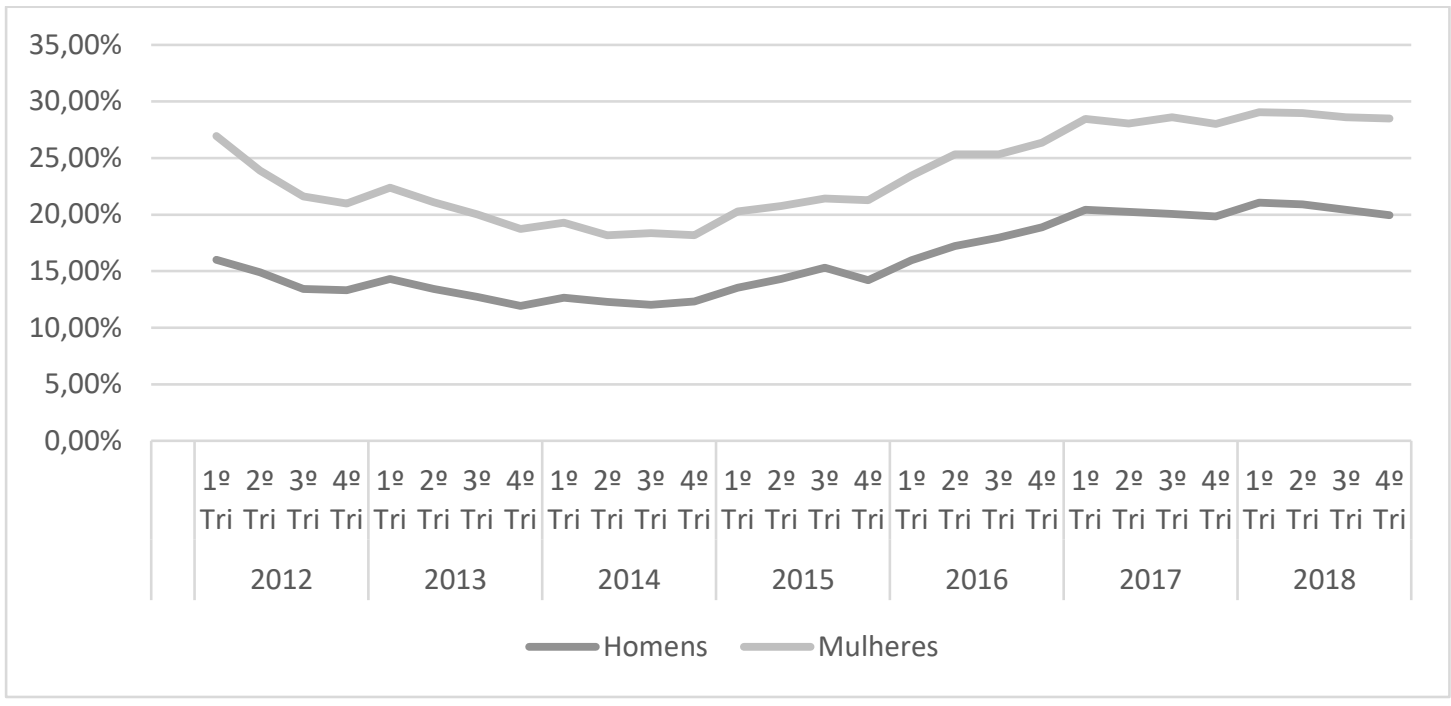

Fonte: PNAD/IBGE. Elaboração própria.

Observamos que desde 2015 há um crescimento do percentual de mulheres subutilizadas, que alcança, no $4^{\circ}$ trimestre de $2018,28 \%$ das mulheres economicamente ativas, em outras palavras, de mulheres subocupadas, desempregadas ou na força de trabalho potencial. Ao trazer para a análise o processo conjuntural do período, vemos que esse aumento ocorre combinado com a diminuição do orçamento para políticas sociais. Portanto, há uma tendência de aprofundamento das condições de precarização das mulheres no mercado de trabalho à medida em que também há um enxugamento da oferta de serviços públicos.

\section{CONCLUSÃO}

A economia feminista vem se colocando como uma disciplina que pretende reinterpretar as análises econômicas clássicas ao questionar os preceitos da objetividade e da neutralidade, apontando que as decisões econômicas se colocam de maneira diferenciada entre os sujeitos sociais, ou seja, a estrutura social interfere na economia bem como a economia interfere na realidade social. Deste modo, para as economistas feministas, a economia não é neutra, e desvendar este caráter possibilita avaliar melhor e mais precisamente os resultados das políticas econômicas.

Nesse sentido, ao ampliarem o conceito de trabalho - identificando que não só a esfera do mercado é que detém força de trabalho e produz valor - afirmam que os papéis sociais construídos em torno do que é ser homem e ser mulher sustentam uma separação 
entre trabalho reprodutivo e produtivo, e estruturam o mercado de trabalho em função destas características. Condicionando assim, a inserção de homens e mulheres sob prisma da divisão sexual do trabalho.

Ao olharmos, sob o viés da econômica feminista, para o processo de recessão econômica e posteriormente à aplicação de um conjunto de políticas de austeridade, identificamos que os dois momentos rebatem de maneira diferenciada para homens e mulheres. $E$ que suas posições sociais servem ao mercado de diferentes formas nos momentos analisados.

No momento da recessão econômica e consequentemente da deterioração de setores mais masculinizados - explicado pela teoria da segmentação do mercado de trabalho - acaba por proteger o emprego feminino num primeiro momento. $E$ até estimulando a inserção delas no mercado de trabalho, com vistas a manter as condições de sobrevivência das famílias, em postos mais precarizados e em setores informais. A diminuição das distâncias entre homens e mulheres nos indicadores é explicado não pela melhoria das condições de trabalho, mas sim pela deterioração geral dos termos do mercado de trabalho brasileiro.

Como vimos a partir de 2015 o governo procurando dar respostas a crise econômica aplica uma política de ajuste fiscal, esperando que os níveis de investimento voltassem a crescer mediante o controle dos gastos públicos. Durante os anos 2000 a implementação de um conjunto de políticas públicas e de distribuição de renda foi fundamental para a inserção qualificada das camadas mais vulneráveis no mercado de trabalho, a diminuição dos gastos públicos representou uma extinção destes fatores, de modo que, para as mulheres a diminuição e o corte de politicas sociais acabou por aprofundar os aspectos da divisão sexual do trabalho, aumentando a carga de trabalho na esfera privada.

Nesse sentido, as mulheres são fortemente afetadas, primeiro por se verem diante da necessidade real de se inserirem na esfera produtiva ante a perda do emprego cônjuge ou da diminuição dos rendimentos familiares decorrente da recessão, ao mesmo tempo que há um desmonte da rede de apoio que possibilita uma inserção no mercado de trabalho com mais autonomia, possibilidade de negociação e igualdade com relação aos homens.

Corroborando com a nossa hipótese os dados nos mostram a elevação do percentual de mulheres subocupadas, ou seja, em empregos de tempo parcial que possibilitem a conciliação das tarefas no âmbito doméstico e do aumento das taxas de subutuilização, em outras palavras, um aumento da deterioração das condições tanto de inserção quanto de permanência das mulheres na esfera produtiva. 
Uma segunda tendência que podemos observar é que o prolongamento da crise econômica, corrói possibilidades empregatícias que tem sido historicamente a alternativa de sustento de um grande contingente de mulheres, sobretudo as mais pobres. Ou seja, a retração orçamentária das famílias - fruto das altas taxas de desemprego, extinção da política de valorização do salário mínimo e retração das taxas de crescimento econômico tende a minar a demanda por serviços tais como o doméstico, e consequentemente aprofundando o desalento entre as mulheres.

Por fim, o que este artigo se pretende é demonstrar que a economia feminista traz subsídios e questionamentos importantes no sentido avançar nas prerrogativas que permeiam as decisões de política econômica. Em outras palavras, reivindica que as tomadas de decisões econômicas devem imprescindivelmente olhar para o corpo social, podendo prever de maneira mais precisa os desdobramentos e resultados. Sendo assim possível, de fato, adotar medidas socialmente justas e efetivas para um real desenvolvimento socioeconômico.

\section{REFERÊNCIAS}

AVILA, Maria Betania de Melo. O tempo do trabalho das empregadas domésticas: entre dominação/exploração e resistência. Tese/Doutorado Programa de PósGraduação em Sociologia. Recife, 2009.

BALTAR, Paulo et al. Trabalho no governo Lula: Uma reflexão sobre a experiência recente. GLOBAL LABOUR UNIVERSITY WORKING PAPERS PAPER NO. 9, May 2010.

BALTAR, Paulo. Crescimento da Economia e mercado de trabalho no Brasil. In Calixtre, A. et al. Presente e Futuro do desenvolvimento brasileiro. Brasília: IPEA, pp- 423-468, 2015.

BECKER, Gary. A theory of the allocation of time. Economic Journal 75 (299): 493-517. 1965.

BRUSCHINI, Cristina. LOMBARDI, Maria Rosa. A bipolaridade do trabalho feminino no Brasil contemporâneo. Cad. Pesqui. [online]. 2000, n.110, pp.67-104. ISSN 0100-1574

CARRASCO, Cristina. A ECONOMIA FEMINISTA: UM PANORAMA SOBRE O CONCEITO DE REPRODUÇÃO. In: Dossiê Economia Feminista. Revista Temáticas, Campinas, 26, (52): 23-30, ago./dez. 2018.

FAGNANI, Eduardo. Notas sobre o desenvolvimento social recente no Brasil. Texto para Discussão n 198. Instituto de Economia UNICAMP, Campinas, 2011. 
FERNANDES, R.; FELÍCIO, F. O ingresso de esposas na força de trabalho como resposta ao desemprego dos maridos: uma avaliação para o Brasil metropolitano. In: Mercado de trabalho no Brasil: salário, emprego e desemprego numa era de grandes mudanças, Rio de Janeiro, 2002.

FREITAS, Taís. Tese (Doutorado em Sociologia) - Universidade Estadual de Campinas. A quem serve a disponibilidade das mulheres? Relações entre gênero, trabalho e família. 2016.

FURNO, Juliane da Costa. A Longa Abolição no Brasil: transformações recentes no trabalho doméstico. Dissertação de Mestrado. Instituto de Economia/UNICAMP, Campinas, 2016.

GRECCO, Fabiana, FURNO, Juliane da Costa; TEIXEIRA, Marilane Oliveira. Apresentação. In: Dossiê Economia Feminista. Revista Temáticas, Campinas, 26, (52): 23-30, ago./dez. 2018.

HIRATA, Helena e HUMPRHEY, John. Trabalhadores Desempregados: Trajetórias de Operárias e Operários Industriais no Brasil. RBCS. v.4, n. 11, outubro de 1989.

HIRATA, Helena. Nova Divisão Sexual do Trabalho? São Paulo: Ed. Boitempo, 2002.

HIRATA, Helena; KERGOAT, Daniele. NOVAS CONFIGURAÇÕES DA DIVISÃO

SEXUAL DO TRABALHO. Cadernos de Pesquisa, v .37. n. 132, p. 595-609. set/dez 2007.

HIRATA, Helena. Mudanças e permanências nas desigualdades de gênero: divisão sexual do trabalho numa perspectiva comparativa. ANÁLISE n 7/2015 Fundação Friedrich-Ebert-Stiftung (FES), São Paulo, 2015.

IBGE - Instituto Brasileiro de Geografia e Estatísticas. Pesquisa Nacional de Amostras de Domicílios (PNAD).

Karamessini, Maria; Rubery, Jill (eds.), Women and Austerity-The Economic Crisis and the Future for Gender and Equality , Londres, Routledge, 2014.

KARTCHEVSKY, Andrée. Introdução. In: O sexo do Trabalho. Rio de Janeiro, Paz e Terra, 1987.

KERGOAT, Danièle. Em defesa de uma sociologia das relações sociais. In. $\mathbf{O}$ sexo do Trabalho. Rio de Janeiro, Paz e Terra, 1987.

KERGOAT, Daniéle. Divisão sexual do trabalho e relações sociais de sexo. In: Trabalho e cidadania ativa para as mulheres. Prefeitura Municipal de São Paulo: Coordenadoria especial da mulher. São Paulo, 2003.

KREIN, José Dari; SANTOS, Anselmo Luis dos; NUNES, Bartira Tardelli. Trabalho no governo Lula: avanços e contradições. Texto para discussão $\mathbf{n}^{\circ} 201$. Instituto de Economia Unicamp. Campinas, Fevereiro, 2012. 
LUNDBERG, S. The Add worker effect: a reappraisal. NBER working paper series, Cambridge, n. 706, 1981.

MELLO, Guilherme. Os primeiros resultados do ajuste: presente sombrio, futuro incerto. In: Ajuste econômico, renúncias fiscais e seguridade social. Revista Social de Desenvolvimento. Ano 3 Maio. 2015.

MILLIOS, J. (2015). Austerity isn't irrational. Jacobin Magazine, Setembro de 2015. Ministério da Educação (BR). Relatório educação para todos no Brasil, 2000-2015. Brasília: MEC; 2014.

Muñoz, L. \& Madroño, P. La desigualdade de género en las crisis económicas. In Investigaciones Feministas, 2011.

NAROTZKY, Susana. Antropología Económica: Nuevas tendências. Melusina, Barcelona 2004.

NOGUEIRA, Claudia Mazzei. O trabalho Duplicado: a divisão sexual do trabalho e na reprodução: um estudo das trabalhadoras de telemarketing. São Paulo: Expressão Popular, 2006.

PICCHIO, Antonella. Trabalho feminino no cerne do mercado de trabalho. In: Dossiê Economia Feminista. Revista Temáticas, Campinas, 26, (52): 23-30, ago./dez. 2018

PICCHIO, Antonella. Social reproduction: the political economy of the labour market. Cambridge: University Press, 1994.

PICCHIO, Antonella. Visibilidad analítica y política Del trabajo de reproducción social. In: Mujeres y Economía: nuevas perspectivas para viejos y nuevos problemas. CARRASCO, Cristina (org). Icaria Antrazyt. Barcelona, 2003.

ROSSI, P. MELLO, G. Componentes Macroeconômicos e Estruturais da Crise Brasileira: o Subdesenvolvimento Revisitado, Brazilian Keynesian Review, 2 (2), p.252-263, 2016.

ROSSI, P. MELLO, G. "Choque recessivo e a maior crise da história: A economia brasileira em marcha à ré". Nota do Cecon, n.1, Abril de 2017.

TEIXEIRA, Marilane Oliveira. Desigualdades salariais entre homens e mulheres a partir da abordagem de economistas feministas. Niterói, Revista Gêneros, v.9, n.1, p. 31-45. Sem 2008.

TEIXERA, Marilane. Formalização do emprego e permanência das desigualdades de gênero. Fundação Friedrich Ebert, São Paulo, 2014.

TEIXERA, Marilane. Tese (Doutorado) - Programa de Pós-Graduação em Desenvolvimento Econômico, Instituto de Economia, Universidade Estadual de Campinas.

Um olhar da economia feminista para as mulheres: os avanços e as permanências das mulheres no mundo do trabalho entre 2004 e 2013. 2017. 
TEIXEIRA, Marilane. A crise econômica e as políticas de austeridade: efeitos sobre as mulheres. In: Economia para Poucos. Impactos Sociais da Austeridade e Alternativas para o Brasil, ROSSI, DWECK \& OLIVEIRA (org). Autonomia Literária. São Paulo, 2018. 